\title{
The Postponement of Motherhood and its Child Health Consequences: Birth Weight and Weight Gain During the First Year of Life
}

\author{
Hideko Matsuo*
}

\begin{abstract}
The postponement of motherhood is one of the most important trends in fertility behaviour in the last few decades. The consequences of late motherhood for child health are not well understood, however. One reason is that in the study of child health, the focus is either on birth (e.g., risk factors for low birth weight), or on child health after birth (e.g., child health consequences of low birth weight). The comprehensive view to child health underlying this paper is that both sides are closely linked. Those perinatal, behavioural and socio-demographic factors which affect birth weight also affect child health after birth. This paper addresses both issues together on the basis of two sets of Belgian regional data. The focus is on the relation between maternal age on the one hand, and birth weight and weight gain after birth (the latter conceptualised in an innovative way) as proxies of child health on the other hand. Our results confirm the importance of high maternal age as a risk factor for low birth weight. They also point to a long-term, though not necessarily permanent, effect of high maternal age on child health after birth for low birth weight children. These results differ from those of studies using other proxies for child health after birth such as physical and cognitive development, which point to permanent negative health effects of low birth weight, and even raise the question of negative intergenerational fertility effects.
\end{abstract}

Hideko Matsuo, Center for Survey Methodology, Department of Sociology, Katholieke Universiteit Leuven, E. Van Evenstraat 2A, Leuven, Belgium. Email: Hideko.Matsuo@soc.kuleuven.be 


\section{Background}

One of the most important trends in fertility behaviour in Europe in the last few decades is the postponement of motherhood, which is reflected in substantial increases in the mean age at first birth (Council of Europe 2004) and the share of live births to mothers aged 35+ (Figure 1). It is to a large extent explained by increases in female educational attainment and labour force participation, and the practical incompatibility between work and motherhood (d'Addio and d'Ercole 2005; Kögel 2004).

The focus of demographic research on postponement has so far been mainly on its negative impact on fertility rates via impaired fecundity and shortened fertility careers. Much less attention has been paid to consequences of the postponement of motherhood on child health. Yet the medical literature has long identified high maternal age as an important risk factor for low birth weight (Bréart 1997), and low birth weight as an important risk factor for weakened child and even adult health (Boardman et al. 2002). To fill this important gap in our knowledge on consequences of postponement, this article studies consequences of high maternal age on child health. It takes a comprehensive view towards child health and at the same time studies the relation between maternal age and birth weight as well as that between maternal age and child health after birth.

Figure 1: Percentage of all live births to mothers aged 35+

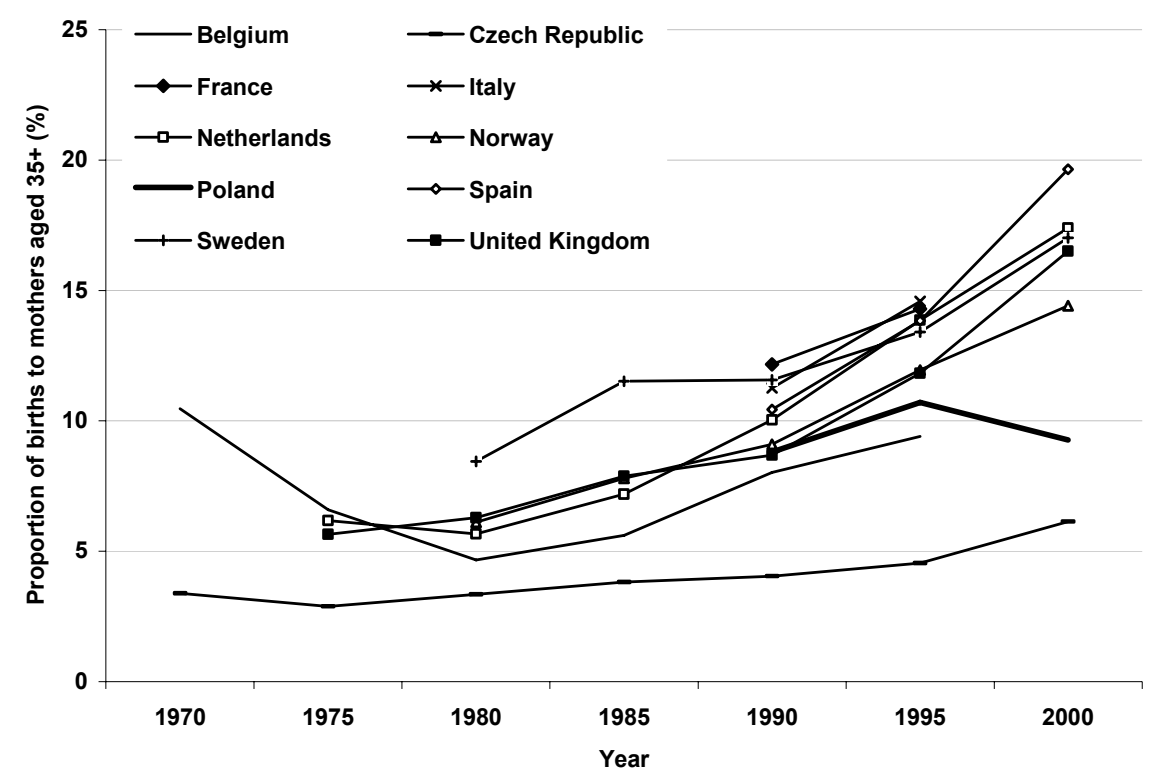

Source: WHO Health for All database statistics, 2005 


\subsection{Maternal Age and Birth Weight}

Over the last few decades, the proportion of births having low birth weight has increased in Europe, largely because of an increasing proportion of births with very low birth weight (Masuy-Stroobant and Gourbin 1995). ${ }^{1}$ The literature has identified a significant number of maternal health related, behavioural and sociodemographic risk factors for (very) low birth weight (Kramer 1987; Kallan 1993), among them maternal age.

The relationship between maternal age and birth weight is complex. Maternal age has first of all an independent effect. Tough et al. (2002), for instance, reported that "with advanced maternal age may be [associated] an impaired functional capacity of [the] uterus, biological ageing, and synergistic effects related to systematic disease"(page 5 of 9).

In addition, maternal age interacts with a large number of behavioural, sociodemographic, and maternal health related factors, which may alternatively strengthen or soften the independent effect of maternal age. Behavioural factors include smoking (Jaakkola et al. 2001; Misra et al. 2005; Kiernan and Pickett 2006). Socio-demographic factors include class, education (Astolfi and Zonta 2002), and income. And maternal health related factors include a prior experience of abortion (Henriet and Kaminski 2001), hypertension (Haelterman et al. 1997), and parity (Hemminki and Gissler 1996; Astolfi and Zonta 2002). Based on the 1991 Finnish Birth Register, Hemminki and Gissler (1996) found, for instance, that low birth weights and pre-term births were mainly found among older primiparous women. Fertility treatment such as IVF also falls into the category of maternal health related factors. Since waiting too long to conceive can result in impaired fertility, more and more use is made of fertility treatment techniques and more and more children are born as a result of such treatment. In Flanders (Belgium), for instance, the share of live births resulting from IVF is increasing (Studiecentrum voor Perinatale Epidemiologie 2005). At least until recently, births resulting from fertility treatments were more likely to be multiple births (Blondel et al. 2002). ${ }^{2}$ And multiple births are more likely to have low birth weights.

The study of the incidence of low birth weight is not problem-free. This has mainly to do with problems stemming from (vital) registration. These exist for low and very low birth weights but become more serious where extremely low birth weights are concerned as the latter are not systematically registered (Buitendijk et al. 2003). Countries are requested to follow WHO recommendations (e.g., reporting all live births and foetal losses from a minimum of $500 \mathrm{~g}$ and 22 weeks of gestation and $25 \mathrm{~cm}$ body length) but legal requirements at the country level and actual practices may not always be in accordance with these recommendations (Gourbin and Masuy-Stroobant 1993; Masuy-Stroobant and Gourbin 1995).

2 Until recently the number of twins as a share of all live births was increasing in Flanders whereas, compared to other European regions and countries, the share of triplet deliveries was also exceptionally high in the period 1985-90 (Masuy-Stroobant 1996). One has to keep in mind that the natural rate (before the onset of IVF practices) of triplet deliveries was for a long 
The relationship between maternal age and low birth weight has been described as U-shaped, which means that the risk of low birth weight is highest at young and high maternal ages (Yang et al. 2006). But while the risk of low birth weight at young maternal ages seems to have been decreasing, that of low birth weight at high maternal ages remains high. Foix-L'Helias and Blondel (2000), for instance, found for France that while a maternal age below 20 years constituted an important risk factor of low birth weight in 1981, this was no longer the case in 1995, while a maternal age above 34 was an important risk factor both in 1981 and 1995. Reichman and Pagnini (1997) found for the US that the high risk of low maternal age (teenage mothers) was more related to socio-economic status than to maternal age as such, while for high maternal age it was more related to age as such, suggesting an independent effect of age. Tough et al. (2002) found for Alberta (Canada) that "delayed childbearing accounted for $78 \%$ of the change in LBW rate in the population and $36 \%$ of the change in preterm delivery rate in the population" (page 1 of 9). Astolfi and Zonta (2002) found on the basis of Italian data that mothers aged $35+$ had a significantly higher risk of still or preterm birth, and of low birth weight at term "even when parity and education variables are controlled for". A US study (First and Second Trimester Evaluation of Risk/FASTER study) showed that mothers aged 40 and above had more low birth weight children and also experienced other negative obstetric outcomes (e.g., foetal/neonatal anomalies, congenital anomalies, preterm delivery) more frequently (Cleary-Goldman et al. 2005).

\subsection{Maternal Age and Weight Gain after Birth}

Compared to the relation between maternal age and birth weight, the relation between maternal age and child health after birth is not well understood. In the literature, maternal age is often not included as an independent variable. Rather, the focus is on variables such as the social and home/family environment. Although such variables clearly are related to maternal age, it is possible that maternal age may be important either independently or in interaction with environmental variables.

At the same time, the literature has usually taken physical and cognitive development (rather than weight gain) as a proxy for child health, the dependent variable. In this paper, however, we take the child's weight gain in the first year of life as a proxy for child health. This appears justified since weight gain provides vital information on the nutritional status of the child. ${ }^{3}$

time around 1 per 10,000 . In 1990 , however, this rate was 5.79 per 10,000 deliveries in Belgium, much higher than in Ireland (1.52), the UK (3.06) or France (4.33), but close to the Netherlands (6.01).

3 See Young (1998) for a discussion of - among other aspects - the physical component of the functional dimension of the health status. 
High maternal age might influence weight gain after birth in two ways: indirectly via its effect on birth weight, which itself influences weight gain after birth, and in a direct manner. We will discuss the impact of high maternal age on weight gain after birth via each of these two channels in comparison with the impact of high maternal age on other proxies for child health after birth.

As for the first channel (via birth weight), the previous discussion made clear that high maternal age probably constitutes a serious risk factor for low birth weight. In studies using other proxies for child health after birth than weight gain after birth, an independent negative effect of low birth weight on subsequent child health has frequently been found. ${ }^{4}$ However, in the literature such an independent negative effect of low birth weight on weight gain after birth has not yet been observed. Low birth weight children generally start catching up with normal birth weight children from immediately after birth. It takes a substantial period of time though before this catch-up is completed. The Quebec Longitudinal Study of Child Development 1998-2002 (Dubois and Girard 2006), for instance, found that low birth weight children generally remain smaller in preschool years (though some low birth weight children, especially those characterised by very rapid weight gain after birth - for instance those whose low birth weight was due to maternal smoking during pregnancy - were actually at risk of obesity) (see also Parsons et al. 2001).

As for the second channel (direct effect), one would expect the children (including low birth weight children) of higher aged mothers to do better in terms of health after birth than those of younger mothers. The reason for this expectation is that child health is crucially affected by the nature of the early home environment, and the extent and quality of caring. Higher aged mothers can be expected, for instance, to be in more stable marital or cohabitation relationships, and have higher levels of educational attainment and more years of work experience, and thus higher levels of income (though on the other hand they may be under more pressure to return quickly to work after giving birth). Still, it is questionable whether an independent effect of high maternal age remains after controlling for such variables. A small positive effect could still be expected because of higher aged mothers' preferences and life course. Higher aged mothers may have made more conscious fertility choices and may thus be more committed mothers. A good example is breastfeeding (Grummer-Strawn and Mei 2004). Higher aged mothers may be more committed to provide breastfeeding and to do so for a longer period of time than younger mothers. At the same time, because of their age, they have been able to observe more other mothers raising children and learn from them.

\footnotetext{
4 See Matsuo 2005, Table 6.
} 


\section{Research Questions and Hypotheses}

This article addresses two related research questions, one on the relation between maternal age and birth weight and one on the relation between maternal age and weight gain after birth.

The first research question of this paper is whether a high maternal age constitutes a significant risk factor for low birth weight. Given the literature discussed above, we hypothesise that high maternal age has an independent negative effect on birth weight, after controlling for other variables, while we hypothesise that a number of variables concerning maternal health (lower gestational age and multiple birth) and socio-demographic aspects (lower socioeconomic status) constitute risk factors for low birth weight as well.

The second research question is what the impact is of high maternal age on weight gain after birth: does it allow a child to maintain ('remain on its curve') or improve ('jump a curve') its weight gain performance after birth, or does it prevent it from doing so ('drop a curve')? Given the literature review above, we hypothesise that low birth weight, to which high maternal age contributes, leads to catch-up (and even overshooting), while the independent effect of maternal age will be small if existing at all after controlling for other variables.

\section{Data}

For the analysis, use was made of two sets of micro-data, made available by two Belgian child welfare agencies, namely Kind \& Gezin $(K \& G)$ and the Office de la Naissance et de l'Enfance (ONE). These sets of micro-data are the only Belgian information systems allowing for the medical follow-up of recently born children and for organising and monitoring preventive care and social support for pregnant and recent mothers. It must be noted that the use of the services provided by both agencies is voluntary. Not all mothers make use of the services offered, which causes immediate attrition compared to the number of births recorded (Table 1).

\subsection{K\&G Data}

The K\&G dataset contains data for almost all children born in the Flemish commune, i.e., in the Flemish region and to the Dutch-speaking population of Brussels. ${ }^{5}$ It covers the years 2001 and 2002. The dataset contains two sections:

The following maternity clinics in Brussels permitted $K \& G$ to visit new mothers and provided information about childbirths taking place there: (1) AZ VUB Jette; (2) Algemeen Ziekenhuis Sint-Jan; (3) Sint-Pieter; (4) Europakliniek Sint-Michiels; (5) Europakliniek Sint-Elisabeth ziekenhuis. It should be noted that this database includes births missing in the national register, e.g. births to non-residents. 
(1) data collected at the time of the child's birth, and (2) data gathered through child follow-up. The first section contains information on the child's situation at the time of birth (date of birth, birth weight, gestational age, etc.) as well as socioeconomic data on the mother (date of birth, nationality at birth, educational attainment, etc.). Some socio-economic information on the father can also be available, but this is often missing. The second section contains child weight, height and head circumference measurements taken at various points after birth (recommended at 2, 3, 4, 5, 7, 10, 12, 15 and 30 months) as part of the health monitoring process conducted both at home and at $\mathrm{K} \& \mathrm{G}$ health extension centres.

Attrition rates are high. While 83 per cent of the children recorded in the database at the time of their birth took part in a first follow-up visit (through a home or consultation bureau visit) within 40 days after birth, for only 60 per cent data were available for age \pm 12 months. Both good and bad health can cause attrition. On the one hand, children free from serious health problems dropping out of the health monitoring process because parents no longer see the added value. On the other hand, attrition could be explained by (limited) mortality and by the fact that children with serious health problems move into more specialised care than $K \& G$ can provide $^{6}$ This last point may explain why attrition disproportionately affects children of low birth weight and low gestational age. This is an important point when drawing conclusions on the basis of this dataset as it raises some questions regarding the possibility of assessing the weight gain performance of the child, particularly among those of low birth weight, via this dataset. Because of high attrition, the characteristics of the follow-up population differ somewhat from those of the baseline population. Low birth weight (in particular, below $1000 \mathrm{~g}$ ) and pre-term (28-36 weeks) children are underrepresented $^{7}$ (Table 1).

\subsection{ONE Data}

The ONE dataset contains data for almost all children born in the French- and German-speaking communes, i.e., in the Walloon region and to the Frenchspeaking population of Brussels in 2000-2001. This dataset also contains two sections: (1) data collected at the time of the child's birth, and (2) data collected at the time of the final contact (usually age 12 months). This means that, whereas $\mathrm{K} \& \mathrm{G}$ data provide follow-up information for the child at different points in time, ONE data provide birth information and follow-up information for the child only for age \pm 52 weeks (approximately 1 year). More extensive child data is available in the ONE dataset than in the K\&G dataset. Data collected at the time of birth

\footnotetext{
According to $\mathrm{K} \& \mathrm{G}$, other reasons are inflexible appointments, busy schedule, preference to visit specialist, etc.

7 It was found that children with very low birth weight (below $1500 \mathrm{~g}$ ) had lower survival status than those who were born with low birth weight (below $2500 \mathrm{~g}$ ).
} 
Table 1:

Descriptive statistics at time of birth and information available at age 330-400 days, Kind en Gezin and ONE

\begin{tabular}{|c|c|c|c|c|c|c|c|c|c|}
\hline \multirow{3}{*}{ Socio-economic variables } & & \multicolumn{4}{|c|}{ At time of birth } & \multicolumn{4}{|c|}{ At age 330-400 days } \\
\hline & & \multicolumn{2}{|c|}{ K\&G } & \multicolumn{2}{|c|}{ ONE } & \multicolumn{2}{|c|}{ K\&G } & \multicolumn{2}{|c|}{ ONE } \\
\hline & & $\mathbf{N}$ & $\%$ & $\mathbf{N}$ & $\%$ & $\mathbf{N}$ & $\%$ & $\mathbf{N}$ & $\%$ \\
\hline \multirow{5}{*}{ Maternal age } & $<20$ years & 1942 & 2.2 & 3526 & 4.1 & 1165 & 2.3 & 702 & 4.7 \\
\hline & $20-29$ years & 47517 & 54.5 & 47226 & 55.1 & 28838 & 55.8 & 8671 & 57.5 \\
\hline & $30-39$ years & 36245 & 41.9 & 33049 & 38.6 & 20991 & 40.6 & 5414 & 35.9 \\
\hline & $40-49$ years & 1225 & 1.4 & 1892 & 2.2 & 724 & 1.4 & 302 & 2.0 \\
\hline & Total & 86569 & 100.0 & 85693 & 100.0 & 51718 & 100.0 & 15089 & 100.0 \\
\hline \multirow{7}{*}{ Maternal nationality } & Belgium & 71184 & 82.2 & 56524 & 66.0 & 42051 & 81.3 & 10703 & 70.9 \\
\hline & Other EU & 3629 & 4.2 & 5761 & 6.7 & 2169 & 4.2 & 961 & 6.4 \\
\hline & Morocco & 3452 & 4.0 & 3069 & 3.6 & 2200 & 4.3 & 475 & 3.1 \\
\hline & Turkish & 2933 & 3.4 & 1755 & 2.0 & 2024 & 3.9 & 415 & 2.7 \\
\hline & Other & 5290 & 6.1 & 4335 & 5.1 & 3239 & 6.3 & 730 & 4.8 \\
\hline & Unknown & 81 & 0.1 & 14249 & 16.6 & 35 & 0.1 & 1805 & 12.0 \\
\hline & Total & 86569 & 100.0 & 85693 & 100.0 & 51718 & 100.0 & 15089 & 100.0 \\
\hline \multirow{6}{*}{ Maternal education } & ISCED 1 & 2667 & 3.1 & & & 1703 & & & \\
\hline & ISCED 2 & 4897 & 5.7 & & & 2995 & 5.8 & & \\
\hline & ISCED $3 / 4$ & 27447 & 31.7 & & & 16233 & 31.4 & & \\
\hline & ISCED 5 & 39169 & 45.2 & & & 22706 & 43.9 & & \\
\hline & Unknown & 12389 & 14.3 & & & 8081 & 15.6 & & \\
\hline & Total & 86569 & 100.0 & & & 51718 & 100.0 & & \\
\hline \multirow{3}{*}{$\begin{array}{l}\text { Poverty (Kansarmoede, } \\
\text { "socially deprived") }\end{array}$} & Yes & 5913 & & & & 3523 & & & \\
\hline & No & 80656 & 93.2 & & & 48195 & 93.2 & & \\
\hline & Total & 86569 & 100.0 & & & 51718 & 100.0 & & \\
\hline \multirow{6}{*}{ Expulsion method } & Spontaneous & & & 61016 & 71.2 & & & 10718 & 71.0 \\
\hline & $\begin{array}{l}\text { Vacuum } \\
\text { extraction }\end{array}$ & & & 6328 & & & & 1156 & 7.7 \\
\hline & Forceps & & & 3163 & 3.7 & & & 638 & 4.2 \\
\hline & Caesarean & & & 15085 & 17.6 & & & 2559 & 17.0 \\
\hline & $\begin{array}{l}\text { Breech } \\
\text { delivery }\end{array}$ & & & 101 & 0.1 & & & 18 & 0.1 \\
\hline & Total & & & 85693 & 100.0 & & & 15089 & 100.0 \\
\hline \multirow{7}{*}{ Marital status } & Married & & & 47195 & 55.1 & & & 8189 & 54.3 \\
\hline & Single & & & 21759 & 25.4 & & & 4140 & 27.4 \\
\hline & $\begin{array}{l}\text { Legally } \\
\text { separated }\end{array}$ & & & 798 & & & & 134 & 0.9 \\
\hline & Widow & & & 149 & 0.2 & & & 28 & 0.2 \\
\hline & Divorced & & & 1212 & 1.4 & & & 230 & 1.5 \\
\hline & Unknown & & & 14580 & 17.0 & & & 2368 & 15.7 \\
\hline & Total & & & 85693 & 100.0 & & & 15089 & 100.0 \\
\hline
\end{tabular}


Table 1( continued)

\begin{tabular}{|c|c|c|c|c|c|c|c|c|c|}
\hline & & \multicolumn{4}{|c|}{ At time of birth } & \multicolumn{4}{|c|}{ At age 330-400 days } \\
\hline & & \multicolumn{2}{|c|}{ K\&G } & \multicolumn{2}{|c|}{ ONE } & \multicolumn{2}{|c|}{ K\&G } & \multicolumn{2}{|c|}{ ONE } \\
\hline & & $\mathbf{N}$ & $\%$ & $\mathbf{N}$ & $\%$ & $\mathbf{N}$ & $\%$ & $\mathbf{N}$ & $\%$ \\
\hline \multirow{6}{*}{$\begin{array}{l}\text { Mother's living } \\
\text { arrangement }\end{array}$} & $\begin{array}{l}\text { Married and } \\
\text { living as } \\
\text { couple }\end{array}$ & & & 45317 & 52.9 & & & 7968 & 52.8 \\
\hline & Cohabiting & & & 19774 & 23.1 & & & 3722 & 24.7 \\
\hline & Living alone & & & 1932 & & & & 403 & 2.7 \\
\hline & Other & & & 1911 & 2.2 & & & 430 & 2.8 \\
\hline & Unknown & & & 16759 & 19.6 & & & 2566 & 17.0 \\
\hline & Total & & & 85693 & 100.0 & & & 15089 & 100.0 \\
\hline \multicolumn{10}{|c|}{ Perinatal variables } \\
\hline \multirow{6}{*}{ Birth weight } & $<1000 \mathrm{~g}$ & 153 & 0.2 & 290 & 0.3 & 72 & 0.1 & 26 & 0.2 \\
\hline & $1000-1499 \mathrm{~g}$ & 424 & 0.5 & 605 & 0.7 & 244 & 0.5 & 69 & 0.5 \\
\hline & $1500-2500 \mathrm{~g}$ & 5039 & 5.8 & 6467 & 7.5 & 2877 & 5.6 & 1127 & 7.5 \\
\hline & $2501 \mathrm{~g}$ plus & 80699 & 93.2 & 78335 & 91.4 & 48525 & 93.8 & 13864 & 91.9 \\
\hline & Unknown & 254 & 0.3 & 0 & 0 & 0 & 2.0 & 3 & 0 \\
\hline & Total & 86569 & 100.0 & 85693 & 100.0 & 51718 & 100.0 & 15089 & 100.0 \\
\hline \multirow{4}{*}{ Gestational age } & $<28$ weeks & 118 & 0.1 & 262 & 0.3 & 57 & 0.1 & 19 & 0.1 \\
\hline & 28-36 weeks & 5857 & 6.8 & 7211 & 8.4 & 3294 & 6.4 & 1180 & 7.8 \\
\hline & $>=37$ weeks & 80594 & 93.1 & 78220 & 91.3 & 48367 & 93.5 & 13890 & 92.1 \\
\hline & Total & 86569 & 100.0 & 85693 & 100.0 & 51718 & 100.0 & 15089 & 100.0 \\
\hline \multirow{4}{*}{ Sex of the child } & Male & 44624 & 51.5 & 43822 & 51.1 & 26501 & 51.2 & 7558 & 50.1 \\
\hline & Female & 41945 & 48.5 & 41732 & 48.7 & 25217 & 48.8 & 7515 & 49.8 \\
\hline & Unknown & 0 & 0.0 & 139 & 0.2 & 0 & 0 & 16 & 0.1 \\
\hline & Total & 86569 & 100.0 & 85693 & 100.0 & 51718 & 100.0 & 15089 & 100.0 \\
\hline \multirow{4}{*}{ Multiple birth } & Singleton & 83630 & 96.6 & 83036 & 96.9 & 50073 & 96.8 & 14625 & 96.9 \\
\hline & Twin or more & 2939 & 3.4 & 2644 & 3.1 & 1645 & 3.2 & 463 & 3.1 \\
\hline & Unknown & 0 & 0 & 13 & 0 & 0 & 0 & 1 & 0.0 \\
\hline & Total & 86569 & 100.0 & 85693 & 100.0 & 51718 & 100.0 & 15089 & 100.0 \\
\hline \multirow{5}{*}{ Parity } & First & 41615 & 48.1 & 37829 & 44.1 & 26096 & 50.5 & 6997 & 46.4 \\
\hline & Second & 29708 & 34.3 & 27583 & 32.2 & 17217 & 33.3 & 4522 & 30.0 \\
\hline & Third or more & 15246 & 17.6 & 19814 & 23.1 & 8405 & 16.3 & 3484 & 23.1 \\
\hline & Unknown & 0 & 0 & 467 & 0.5 & 0 & 0 & 86 & 0.6 \\
\hline & Total & 86569 & 100.0 & 85693 & 100.0 & 51718 & 100.0 & 15089 & 100.0 \\
\hline
\end{tabular}

include weight, height, head circumference, gestational age, parity, multiple birth and gender. Data collected at the time of the final contact also include vaccination status, psycho-motor development, etc. The socio-demographic information collected for the mother differs somewhat from that in the K\&G dataset. Unlike the $K \& G$ dataset, the ONE dataset does not include information on the educational background of the mother. However, the ONE dataset includes information on marital status and the living arrangement of the mother which the $\mathrm{K} \& \mathrm{G}$ dataset does not.

Just as in the K\&G dataset, and for the same reasons, attrition rates are high. After 52 weeks, follow-up information was available only for 17.6 per cent of the 
original sample. ${ }^{8}$ In addition to the fact that-like in the K\&G dataset-low birth weight and pre-term children are under-represented in the follow-up population as compared to the baseline population, there is an over-representation of younger mothers $(<20$ years) and an under-representation of higher-aged ones $(35+)$. There is also an over-representation of women of single marital status and women living in couples (cohabitors), as well as Belgian and Turkish women, while there is an under-representation of Moroccan ones (Table 1). We will discuss the potential consequences of selective attrition in the discussion?.

\section{Variables}

\subsection{Variable Included in the Analysis of Birth Weight}

\section{$K \& G$ data}

Birth weight data was missing for $3.5 \%$ of children. If missing, it was assumed that the weight measured at the time of the first contact (usually within 2 weeks after birth) was the birth weight. Next, all birth weights were assigned to 2 categories: (0) $2500 \mathrm{~g}$ and above, and (1) below $2500 \mathrm{~g}$. Some 93 per cent of children were of normal birth weight. While the share of children with a birth weight between 1500 and 2500 grams was not negligible (5.8\%), the shares of children with birth weights between 1000 and 1500 grams $(0.5 \%)$ and of those with even lower birth weights $(0.2 \%)$ were much smaller.

Mothers were classified in ten-year age groups. Most fell into the age group 20-29 years (54.5 per cent), though the share of the 30-39 age group (41.9 per cent) was high as well. Gestational age, sex, multiple birth, parity, maternal education, maternal nationality and poverty status were used as control variables. Most children were born at or above 37 weeks (93.1 per cent). There were

8 To be consistent with the K\&G dataset, however, only those for whom this last contact took place between 330 and 400 days after birth were taken into account.

9 It is important to note that attrition is not only a problem in the ONE and K\&G datasets, but is frequently affecting longitudinal studies. For instance, in the well-known UK millennium cohort study, which rigorously followed up on the health status of children born in the period 2000-2002, only 72 per cent of children aged nine months could be traced (Walton et al. 2006). Attrition is usually not random and frequently results in an eventual over-representation of lower socio-economic groups (selection effect). In one study on the two-year health outcome of infants weighing 600 grams or less at birth (Sweet et al. 2003), for instance, all mothers were of low socio-economic origin, whether measured by race, marital status, the receipt of social assistance, or tobacco use. A selection effect may result from the fact that higher socioeconomic groups are likely to engage in behaviour which can possibly give rise to low birth weight (smoking, drinking, drugs, etc.). Also, if a low birth weight child is born to women in these groups, they may prefer not to pursue aggressive health treatments since they are better able to assess the possible negative impacts of low birth weight on later child health and on their own lives. Or they may drop out from regular publicly provided follow-up consultations, preferring to have their child diagnosed by more specialized doctors. 
somewhat more boys than girls. Most births were singletons (96.6 per cent) and first births (48.1 per cent), even though second ( 34.3 per cent), as well as third and higher parities (17.6 per cent) were not uncommon. High average maternal education levels (ISCED3/4: 31.7 per cent; ISCED5: 45.2 per cent) reflect that education in Belgium is compulsory until age 18. However, a substantial proportion $(14.3 \%)$ of mothers did not report their level of education. Most mothers were of Belgian nationality (82.2 per cent) and did not suffer from poverty (kansarmoede or "socially deprived" variable, 93.2 per cent) (Table 1).

\section{ONE data}

In contrast to the $\mathrm{K} \& \mathrm{G}$ dataset, birth weight data was complete in the ONE dataset. Birth weights were assigned to 2 categories: (0) $2500 \mathrm{~g}$ and above, and (1) below $2500 \mathrm{~g}$. The great majority of children (91.4 per cent) were of normal birth weight. While the share of children with a birth weight between 1500 and 2500 grams was not negligible ( 7.5 per cent), the shares of children with birth weights between 1000 and 1500 grams ( 0.7 per cent) and of those with even lower birth weights were much smaller ( 0.3 per cent). Note, however, that the proportion of low birth weight children was slightly higher in the ONE dataset than in the $K \& G$ one.

Like in the $\mathrm{K} \& \mathrm{G}$ dataset, most mothers fell into the age group 20-29 (55.1 per cent), though the share of the age group 30-39 was not negligible (38.6 per cent). The proportion of teen-age mothers was higher and that of older mothers (30-39 years) lower than in the $K \& G$ dataset. In addition to some of the control variables taken for the $\mathrm{K} \& \mathrm{G}$ dataset (gestational age, sex, multiple birth, parity, and maternal nationality), mode of delivery, maternal marital status and maternal living arrangement (self-calculated) were also included as control variables. Most children were born at or above 37 weeks ( 91.3 per cent). The dataset contained somewhat more boys than girls. By far most children born were singletons (96.9 per cent). Most births were first births (44.1 per cent), even though second (32.2 per cent), as well as third and higher parities (23.1 per cent - substantially higher than in the $K \& G$ dataset) were not uncommon. Most mothers, though far less than in the $\mathrm{K} \& \mathrm{G}$ dataset, were of Belgian nationality (66.0 per cent). However, substantial proportions of mothers came from other EU countries (6.7 per cent). Most children were delivered naturally, though the proportion of caesarian births (17.6 per cent) was also high. Most mothers were legally married or legally single but living together (cohabiters). However, it must be noted that for a number of socio-economic variables (ex. marital status, living arrangement, and nationality) the number of 'unknown' cases was significant (Table 1). 


\subsection{Variables Included in the Analysis if Weight Gain after Birth}

\section{$K \& G$ data}

The perinatal and socio-demographic characteristics of the subset of children for whom follow-up information was available on the situation at age \pm 1 year did not differ very much from those of the total of children for whom information was available on the situation at birth. The majority ( 93.8 per cent) was of normal birth weight. The share of children with a birth weight between 1500 and 2500 grams was 5.6 per cent, that of children with a birth weight between 1000 and 1500 grams 0.5 per cent, and that of children with even lower birth weights 0.1 per cent. Most mothers fell into the age category 20-29 years (55.8 per cent), with the age group 30-39 years coming second (40.6 per cent). Most children were born at or above 37 weeks ( 93.5 per cent), and there were somewhat more boys than girls. Most births were singletons (96.8 per cent) and first births (50.5 per cent). Second births accounted for 33.3 per cent, while third and higher parities accounted for 16.3 per cent. Levels of maternal educational attainment remained high (ISCED3/4: 31.4 per cent; ISCED5: 43.9 per cent), though the number of 'unknown' cases was high at 15.6 per cent. Most mothers had the Belgian nationality ( 81.3 per cent) and did not suffer from poverty (Table 1$)$.

\section{ONE data}

Like in the $K \& G$ dataset, characteristics did not differ very much between the subset of children for whom follow-up information was available and the total sample. The large majority of 'follow-up children' ( 91.9 per cent) were of normal birth weight. Those with a birth weight between 1500 and 2500 grams accounted for 7.5 per cent, those with a birth weight between 1000 and 1500 grams for 0.5 per cent, and those with even lower birth weights for 0.2 per cent. Like in the $\mathrm{K} \& \mathrm{G}$ dataset, most 'follow-up mothers' fell into the age group of 20-29 years (57.5 per cent), though the share of the 30-39 age group was not negligible at 35.9 per cent. Most 'follow-up children' were born at or above 37 weeks (92.1 per cent). There were more boys than girls. Most births were singletons (96.9 per cent) and first births (46.4 per cent). Most 'follow-up mothers' were of Belgian nationality ( 70.9 per cent), while the share of other nationalities ( 4.8 per cent) and of 'unknown' cases slightly decreased (12.0 percent). Most 'follow-up' children were delivered naturally, their share not differing very much from that for the total sample. Most 'follow-up mothers' were legally married but a slight increase was found in the proportion of cohabiting couples (Table 1).

The operationalisation of the dependent variable-making use of growth curves To study relative weight gain during the first year, use was made of growth curves. Basically, the procedure boiled down to calculating whether or not the weight gain during the first year of a child with a certain birth weight fitted the growth curve for children with that birth weight. If growth was slower than 
expected, weight gain was classified as being (too) low (see also Mei et al. 2004). However, given the absence of growth curves for children with low birth weight, slightly different procedures were used for children with normal and children with low birth weight.

Normal birth weight children were assigned to one of eight different categories on the basis of a matching of their birth weight with the most recent growth curves for Flemish boys and girls (Flemish growth curve 2005): (1) up to the 3 rd percentile; (2) between the 3 rd and the $10^{\text {th }}$ percentile; (3) between the $10^{\text {th }}$ and the $25^{\text {th }}$ percentile; (4) between the $25^{\text {th }}$ and the $50^{\text {th }}$ percentile; (5) between the $50^{\text {th }}$ and the $75^{\text {th }}$ percentile; (6) between the $75^{\text {th }}$ and the $90^{\text {th }}$ percentile; (7) between the $90^{\text {th }}$ and the $97^{\text {th }}$ percentile; and (8) above the $97^{\text {th }}$ percentile. Because of a lack of recent Walloon growth curves, the most recent Flemish growth curves were used to operationalise the dependent variable in both the $K \& G$ and the ONE datasets.

For low birth weight children, a slightly different procedure was used. First, the average rate of weight increase between the time of birth and age 12 months was calculated for normal birth weight children and this rate was subsequently applied to the birth weights 500, 1000, 1500, 2000 and 2500 grams to obtain new growth curves [For the complexity of calculating appropriate growth curves for low birth weight children, see Sherry et al. (2003)]. Next, each low birth weight child was assigned to one of five different categories on the basis of a matching of their birth weight with those newly formulated growth curves: (1) birth weight up to $500 \mathrm{~g}$, (2) birth weight between $500 \mathrm{~g}$ and $1000 \mathrm{~g}$, (3) birth weight between $1000 \mathrm{~g}$ and $1500 \mathrm{~g}$, (4) birth weight between $1500 \mathrm{~g}$ and $2000 \mathrm{~g}$, and (5) birth weight between $2000 \mathrm{~g}$ and $2500 \mathrm{~g}$.

For normal as well as low birth weight children, this exercise was repeated for the child's weight at age 12 months. Again, normal birth weight children were classified in eight categories, and low birth weight children in five categories. Finally, the dependent variable was calculated by comparing the classification of children at birth and after 12 months. Children who had stayed within the same category or had increased a category were coded 0 , while children who had dropped down a category were coded 1 .

\section{Method of Analysis}

To answer the two research questions, a number of logistic regression analyses were carried with low birth weight (versus normal birth weight) and low weight gain (versus normal weight gain) as dependent variables. First, separately for the $\mathrm{K} \& \mathrm{G}$ and the ONE dataset, the relation between maternal age and birth weight was analysed. This analysis was first carried out for all children (1). Subsequently, the same analysis was performed for specific subgroups of children: (2) only children of women aged 20 or more; (3) only children of 
women aged 35 or more; (4) only children of primiparous women; (5) only children of primiparous women aged 20 or more; (6) only children of primiparous women aged 35 or more). This resulted in 12 different specifications (6 each). Given space restrictions, only results for multiparous and for primiparous women will be presented. Other interesting findings will be commented on in the text. Next, an analysis was carried out on the relation between maternal age and weight gain after birth (maintaining/improving vs. worsening weight gain performance), following a similar logic. After an analysis carried out for all children, once more different restrictions (this time also referring to low birth weight) were introduced. Again, only results for multiparous and primiparous women will be presented.

\section{Results}

\subsection{Maternal Age and Birth Weight}

\section{$K \& G$ data}

The analysis carried out for all children confirmed that high age is indeed an important risk factor for low birth weight (Table 2). For women aged 30-39, the $\log$ odds of having a low birth weight birth (and thus the risk) was 0.09 (factor 1.10) higher than for women aged 20-29, and for women aged 40-49 even higher: 0.33 (factor 1.39) $(\mathrm{p}<0.01)$. The analysis also confirmed the negative impact of some well-known perinatal risk factors discussed in the background section at the beginning of this paper. The log of odds was 2.38 (factor 10.84) higher for twins and other multiple births than for singletons, for instance, while a lower gestational age clearly increased the risk of low birth weight. The effect of maternal educational attainment was mixed. While ISCED2 increased the log of odds (and thus the risk) by 0.23 (factor 1.26) compared to a low level of educational attainment (ISCED1), a high level of educational attainment (ISCED5) decreased the log of odds (and thus the risk) by 0.50 (factor 0.61 ). Being of non-Belgian nationality (Moroccan, Turkish, non-Belgian EU) reduced the risk of low birth weight, a phenomenon well-described in the literature (Buekens et al. 1998). Absence of poverty also reduced the risk of low birth weight.

When restricting the analysis to children of women aged 35 or more, the risk of low birth weight associated with a low level of educational attainment (ISCED2) was further increased. When restricting the analysis to children of primiparous women, significant results were obtained in line with the baseline analysis; only nationality was not significant. 


\section{ONE data}

The analysis carried out for all children in the ONE dataset also confirmed high age as an important risk factor for low birth weight (Table 3). Results were significant at the variable level, as well as for the 40-49 age group. The importance of perinatal risk factors was also confirmed. For twins and other multiple births, the log of odds (and thus the risk) was 2.09 (factor 8.08) higher than for singletons. Lower gestational age strongly increased the risk and higher parity reduced it. Deliveries by caesarean section increased the risk, since they probably point to problematic pregnancies/deliveries. Being unmarriedespecially being legally separated or widowed-also increased the risk of low birth weight, another phenomenon frequently described in the literature (Raatikainen et al. 2005). The results obtained for nationality were in line with those obtained for the K\&G dataset. Compared to being of Belgian nationality, being of another EU, Moroccan or other nationality decreased the risk, while the results for the Turkish population were not significant.

The results for primiparous women show that both having a child early (as a teenager) and having a child late in life (from age 40 onwards) increase the risk of giving birth to a child with low birth weight. In particular the latter group of women showed a very elevated risk of having low birth weight children. When restricting the analysis to children of mothers aged 35 or more, results comparable to those of the baseline analysis were obtained for delivery by caesarean section, the risk associated with breech delivery was high, and the negative effect of not being married also increased.

\subsection{Maternal Age and Weight Gain after Birth}

\section{$K \& G$ data}

When carrying out the analysis for all children, no significant results were obtained for age (Table 2), suggesting that mother's age at birth as such does not influence weight gain during the first year of the child's life. Significant results were obtained, however, for all other independent variables. A low birth weight decreased the risk of dropping a weight category. A higher parity birth and being of female sex increased the risk of dropping a weight category, while twins and other multiple births decreased the risk. For instance, the log of odds (and thus the risk) was 0.49 (factor 1.64) higher for second parity and 0.72 (factor 2.06) for third or higher parity. Contrary to expectations, low levels of educational attainment (ISCED2) decreased the risk. Being of non-Belgian (especially of Moroccan or Turkish) nationality decreased the risk, while poverty increased it.

When restricting the analysis to children of primiparous women, a low birth weight substantially reduced the risk (in a significant manner). Levels of maternal educational attainment were significant at the level of the variable as a whole and at the level of ISCED5 and increased the risk. When restricting the analysis to children of women aged 35 or more, findings similar to those of the baseline 
Table 2:

Results on logistic regression analysis (1) maternal age and birth weight and (2) maternal age and weight gain based on the analysis of Kind en Gezin

\begin{tabular}{|c|c|c|c|c|c|c|c|c|}
\hline \multirow{3}{*}{ KG } & \multicolumn{4}{|c|}{ Maternal age and birth weight (1) } & \multicolumn{4}{|c|}{ Maternal age and weight gain (2) } \\
\hline & \multicolumn{2}{|c|}{$\begin{array}{c}\text { Multiparous } \\
\text { mothers }\end{array}$} & \multicolumn{2}{|c|}{$\begin{array}{c}\text { Primiparous } \\
\text { women }\end{array}$} & \multicolumn{2}{|c|}{$\begin{array}{c}\text { Multiparous } \\
\text { mothers }\end{array}$} & \multicolumn{2}{|c|}{$\begin{array}{c}\text { Primiparous } \\
\text { women }\end{array}$} \\
\hline & B & $\operatorname{Exp}(B)$ & B & $\operatorname{Exp}(B)$ & B & $\operatorname{Exp}(B)$ & B & $\operatorname{Exp}(B)$ \\
\hline Maternal age & \multicolumn{2}{|c|}{$(0.00)$} & \multicolumn{2}{|c|}{$(0.00)$} & \multicolumn{2}{|c|}{$(0.15)$} & \multicolumn{2}{|c|}{$(0.49)$} \\
\hline RC: $20-29$ years & 0 & 1 & 0 & 1 & 0 & 1 & 0 & 1 \\
\hline$<20$ years & -0.18 & 0.83 & -0.15 & 0.86 & -0.09 & 0.92 & -0.09 & 0.92 \\
\hline $30-39$ years & 0.09 & $1.10 * *$ & 0.23 & $1.26^{* *}$ & 0.06 & $1.07 *$ & 0.07 & 1.07 \\
\hline $40-49$ years & 0.33 & $1.39 * *$ & 0.31 & 1.36 & -0.05 & 0.95 & 0.19 & 1.21 \\
\hline \multicolumn{9}{|l|}{ Birth weight } \\
\hline $\mathrm{RC}:>=2500 \mathrm{~g}$ & & & & & 0 & 1 & 0 & 1 \\
\hline$<2500 \mathrm{~g}$ & & & & & -3.68 & $0.03 * *$ & -4.76 & $0.01 * *$ \\
\hline Gestational age & \multicolumn{2}{|c|}{$(0.00)$} & \multicolumn{2}{|c|}{$(0.00)$} & \multicolumn{2}{|c|}{$(0.00)$} & \multicolumn{2}{|c|}{$(0.00)$} \\
\hline RC: $37+$ weeks & 0 & 1 & 0 & 1 & 0 & 1 & 0 & 1 \\
\hline 28-36 weeks & 3.43 & $30.80 * *$ & 3.50 & $33.11 * *$ & -1.73 & $0.18 * *$ & -1.59 & $0.20 * *$ \\
\hline$\leq 28$ weeks & 5.36 & $211.88^{* *}$ & 5.52 & $248.61 * *$ & -0.44 & 0.65 & -16.42 & 0.00 \\
\hline \multicolumn{9}{|l|}{ Gender } \\
\hline RC: Male & 0 & 1 & 0 & 1 & 0 & 1 & 0 & 1 \\
\hline Female & 0.52 & $1.68^{* *}$ & 0.49 & $1.63^{* *}$ & 0.48 & $1.62 *$ & 0.55 & $1.73 * *$ \\
\hline Multiple birth & & & & & & & & \\
\hline RC: singletons & 0 & 1 & 0 & 1 & 0 & 1 & 0 & 1 \\
\hline Twin or more & 2.38 & $10.84 * *$ & 2.19 & $8.93 * *$ & -2.23 & $0.10^{* *}$ & -3.06 & $0.05 * *$ \\
\hline Parity & \multicolumn{2}{|c|}{$(0.00)$} & & & \multicolumn{2}{|c|}{$(0.00)$} & & \\
\hline RC: First & 0 & 1 & & & 0 & 1 & & \\
\hline Second & -0.51 & $0.60 * *$ & & & 0.49 & $1.64 * *$ & & \\
\hline Third or more & -0.59 & $0.56 * *$ & & & 0.72 & $2.06 * *$ & & \\
\hline Maternal education & \multicolumn{2}{|c|}{$(0.00)$} & \multicolumn{2}{|c|}{$(0.00)$} & \multicolumn{2}{|c|}{$(0.00)$} & \multicolumn{2}{|c|}{$(0.00)$} \\
\hline RC: ISCED1 & 0 & 1 & 0 & 1 & 0 & 1 & 0 & 1 \\
\hline ISCED 2 & 0.23 & $1.26^{*}$ & -0.02 & 0.98 & -0.26 & $0.77 * *$ & 0.15 & 1.16 \\
\hline ISCED3/4 & -0.08 & 0.92 & -0.22 & 0.80 & -0.13 & 0.88 & 0.23 & 1.25 \\
\hline ISCED 5 & -0.50 & $0.61 * *$ & -0.58 & $0.56^{* *}$ & 0.15 & 1.16 & 0.47 & \\
\hline Unknown & -0.14 & 0.87 & -0.34 & $0.71 *$ & -0.09 & 0.92 & 0.17 & 1.18 \\
\hline Mother's nationality & \multicolumn{2}{|c|}{$(0.00)$} & $(0.2$ & & $(0$. & & $(0$. & \\
\hline RC: Belgium & 0 & 1 & 0 & 1 & 0 & 1 & 0 & 1 \\
\hline Other EU & -0.01 & 0.99 & 0.06 & 1.07 & -0.08 & 0.92 & -0.17 & 0.85 \\
\hline Morocco & -0.30 & $0.74 * *$ & -0.17 & 0.84 & -0.26 & $0.77 * *$ & -0.28 & $0.75^{*}$ \\
\hline Turkish & -0.26 & $0.77 * *$ & 0.05 & 1.06 & -0.61 & $0.54 * *$ & -0.45 & $0.64 * *$ \\
\hline Other & -0.21 & $0.81 * *$ & -0.22 & $0.81 *$ & -0.27 & $0.76^{* *}$ & -0.19 & 0.83 \\
\hline Unknown & 0.77 & 2.16 & 0.73 & 2.08 & -0.06 & 0.94 & -0.10 & 0.90 \\
\hline Poverty & & & & & & & & \\
\hline RC: NO & 0 & 1 & 0 & 1 & 0 & 1 & 0 & 1 \\
\hline YES & -0.69 & $0.50 * *$ & -0.56 & $0.57 * *$ & 0.20 & $1.22 * *$ & 0.38 & $1.46^{* *}$ \\
\hline Constant & -2.83 & $0.06^{* *}$ & -2.87 & $0.06^{* *}$ & -2.43 & $0.03 * *$ & -2.97 & $0.05 * *$ \\
\hline
\end{tabular}

Note: Significance level for the variable as a whole is expressed in brackets; ${ }^{*}=\mathrm{p}<0.05 ; * *=\mathrm{p}<0.01$. 
analysis were found for perinatal factors, while significant results were found for education at the level of the variable as a whole, and no significant results were obtained any more for nationality.

\section{ONE data}

When carrying out the analysis for all children included in the dataset, children of mothers who had their child between ages 30 and 39 showed a slightly increased risk of experiencing a low weight gain (Table 3). However, unlike for the K\&G dataset, no significant results were obtained for low birth weight. Significant results were found for gestational age, gender, parity and delivery method. Lower gestational age (28-36 weeks) decreased the risk of experiencing a downward movement, while being female, being a second or third or higher parity, and breech deliveries and vacuum extraction increased the risk. As for the sociodemographic control variables, significant results were found for nationality. Being a non-Belgian mother, especially being Turkish, decreased the risk.

Further, a limited number of significant effects were found when restricting the analysis to primiparous women. In particular, the elevated risk of low weight gain for women who were 30-39 at birth was even stronger than in the analysis for all women. For women aged 30-39, the log of odds (and thus the risk) was 0.42 (factor 1.52) higher than for women aged 20-29 ( $<<0.01)$. A significant and increased risk was found for breech delivery and caesarean method as well.

\section{Conclusion and Discussion}

This study examined how the mother's age at birth influences birth weight and weight gain during the first year of children born in Flanders and Wallonia, the two main parts of Belgium. It clearly demonstrated the potential use of regional birth weight and child health micro-data of a longitudinal nature. Our study is also unique in the sense that it makes use of recent regional growth charts to monitor the weight gain of the child after birth.

A number of interesting results were obtained. The first research question focussed on the impact of high maternal age on birth weight. The analysis of both datasets confirmed that, in accordance with our hypothesis, high maternal age is indeed an important risk factor for low birth weight. In the Flemish data women who got a child after the age of 30 already ran an increased risk of having a child with a low birth weight, whereas in the Walloon data, this risk was increased only for women over age 40. The second research question focussed on the impact of high maternal age on weight gain after birth. The analysis of the Flemish dataset showed that low birth weight decreased the risk of a deteriorating weight performance. This suggests an indirect effect of age at motherhood, as older mothers are more likely to have a child with low birth weight. Indications of a direct effect of maternal age were only found in the analysis of the Walloon 
Table 3:

Results on logistic regression analysis (1) maternal age and birth weight and (2) maternal age and weight gain, based on the analysis of $\mathrm{ONE}$

\begin{tabular}{|c|c|c|c|c|c|c|c|c|}
\hline \multirow{3}{*}{ ONE } & \multicolumn{4}{|c|}{ Maternal age and birth weight } & \multicolumn{4}{|c|}{ Maternal age and weight gain } \\
\hline & \multicolumn{2}{|c|}{$\begin{array}{c}\text { Multiparous } \\
\text { mothers }\end{array}$} & \multicolumn{2}{|c|}{$\begin{array}{c}\text { Primiparous } \\
\text { women }\end{array}$} & \multicolumn{2}{|c|}{$\begin{array}{c}\text { Multiparous } \\
\text { mothers }\end{array}$} & \multicolumn{2}{|c|}{$\begin{array}{c}\text { Primiparous } \\
\text { women }\end{array}$} \\
\hline & B & $\operatorname{Exp}(B)$ & B & $\operatorname{Exp}(B)$ & B & $\operatorname{Exp}(B)$ & B & $\operatorname{Exp}(B)$ \\
\hline Maternal age & \multicolumn{2}{|c|}{$(0.04)$} & \multicolumn{2}{|c|}{$(0.03)$} & \multicolumn{2}{|c|}{$(0.10)$} & \multicolumn{2}{|c|}{$(0.05)$} \\
\hline RC: $20-29$ & 0 & 1 & 0 & 1 & 0 & 1 & 0 & 1 \\
\hline$<20$ & 0.14 & 1.15 & 0.17 & $1.19^{*}$ & -0.45 & 0.64 & -0.27 & 0.76 \\
\hline $30-39$ & 0.00 & 1.00 & 0.08 & 1.09 & 0.17 & $1.18^{*}$ & 0.42 & $1.52^{* *}$ \\
\hline 40-49 & 0.26 & $1.30 * *$ & 0.48 & $1.61 *$ & -0.15 & 0.86 & -18.06 & 0.00 \\
\hline \multicolumn{9}{|l|}{ Birth weight } \\
\hline $\mathrm{RC}:>=2500 \mathrm{~g}$ & & & & & 0 & 1 & 0 & 1 \\
\hline$<2500 \mathrm{~g}$ & & & & & -17.61 & 0.00 & 17.31 & 0.00 \\
\hline Gestational age & \multicolumn{2}{|c|}{$(0.00)$} & \multicolumn{2}{|c|}{$(0.00)$} & \multicolumn{2}{|c|}{$(0.00)$} & \multicolumn{2}{|c|}{$(0.10)$} \\
\hline RC: $37<$ wks & 0 & 1 & 0 & 1 & 0 & 1 & 0 & 1 \\
\hline 28-36 weeks & 3.08 & $21.85^{* *}$ & 3.18 & $23.93 * *$ & -1.41 & $0.24 * *$ & -1.55 & $0.21 *$ \\
\hline$<28$ weeks & 5.69 & $296.03 * *$ & 5.60 & $270.73 * *$ & -14.71 & 0.00 & -1.02 & 0.36 \\
\hline \multicolumn{9}{|l|}{ Gender } \\
\hline RC: Male & 0 & 1 & 0 & 1 & 0 & 1 & 0 & 1 \\
\hline Female & 0.40 & $1.49 * *$ & 0.39 & $1.48 * *$ & 0.51 & $1.67 * *$ & 0.56 & $1.74 * *$ \\
\hline Multiple birth & \multicolumn{2}{|c|}{$(0.00)$} & \multicolumn{2}{|c|}{$(0.00)$} & \multicolumn{2}{|c|}{$(0.13)$} & \multicolumn{2}{|c|}{$(1.00)$} \\
\hline RC: Singleton & 0 & 1 & 0 & 1 & 0 & 1 & 0 & 1 \\
\hline Twin or more & 2.09 & $8.08^{* *}$ & 2.21 & $9.13 * *$ & -1.20 & $0.30^{*}$ & -16.96 & 0.00 \\
\hline Unknown & 4.06 & $58.20 * *$ & 3.71 & $41.02 * *$ & -1.18 & 0.31 & -1.38 & 0.25 \\
\hline Parity & \multicolumn{2}{|c|}{$(0.00)$} & & & \multicolumn{2}{|c|}{$(0.00)$} & & \\
\hline RC: First & 0 & 1 & & & 0 & 1 & & \\
\hline Second & -0.32 & $0.73 * *$ & & & 0.55 & $1.74 * *$ & & \\
\hline Third or more & -0.17 & $0.84 * *$ & & & 0.56 & $1.76^{* *}$ & & \\
\hline Unknown & 0.08 & 1.09 & & & & & & \\
\hline
\end{tabular}

Table to be continued on the next page 
Table 3 (continued)

\begin{tabular}{|c|c|c|c|c|c|c|c|c|}
\hline \multirow[b]{3}{*}{ ONE } & \multicolumn{4}{|c|}{ Maternal age and birth weight } & \multicolumn{4}{|c|}{ Maternal age and weight gain } \\
\hline & \multicolumn{2}{|c|}{$\begin{array}{c}\text { Multiparous } \\
\text { mothers }\end{array}$} & \multicolumn{2}{|c|}{$\begin{array}{c}\text { Primiparous } \\
\text { women }\end{array}$} & \multicolumn{2}{|c|}{$\begin{array}{l}\text { Multiparous } \\
\text { mothers }\end{array}$} & \multicolumn{2}{|c|}{$\begin{array}{c}\text { Primiparous } \\
\text { women }\end{array}$} \\
\hline & B & $\operatorname{Exp}(B)$ & B & $\operatorname{Exp}(B)$ & B & $\operatorname{Exp}(B)$ & B & $\operatorname{Exp}(B)$ \\
\hline $\begin{array}{l}\text { Mother's living } \\
\text { arrangement }\end{array}$ & \multicolumn{2}{|c|}{$(0.00)$} & \multicolumn{2}{|c|}{$(0.00)$} & \multicolumn{2}{|c|}{$(0.09)$} & \multicolumn{2}{|c|}{$(0.34)$} \\
\hline living as couple & 0 & 1 & 0 & 1 & 0 & 1 & 0 & 1 \\
\hline Cohabiting & -0.08 & 0.93 & -0.11 & 0.89 & 0.63 & 1.87 & 0.88 & 2.42 \\
\hline Living alone & 0.16 & 1.17 & 0.31 & 1.36 & 0.02 & 1.02 & 0.92 & 2.51 \\
\hline Other & 0.22 & 1.25 & 0.28 & 1.32 & -0.17 & 0.84 & -0.55 & 0.58 \\
\hline Unknown & -0.05 & 0.95 & -0.03 & 0.97 & 0.51 & 1.67 & 0.49 & 1.63 \\
\hline Mother's nationality & \multicolumn{2}{|c|}{$(0.00)$} & \multicolumn{2}{|c|}{$(0.06)$} & \multicolumn{2}{|c|}{$(0.03)$} & \multicolumn{2}{|c|}{$(0.64)$} \\
\hline RC: Belgium & 0 & 1 & 0 & 1 & 0 & 1 & 0 & 1 \\
\hline Other EU & -0.15 & $0.86^{*}$ & -0.21 & $0.81 *$ & -0.38 & $0.68^{*}$ & -0.13 & 0.88 \\
\hline Morocco & -0.32 & $0.73 * *$ & -0.09 & 0.91 & -0.25 & 0.78 & 0.12 & 1.13 \\
\hline Turkish & -0.19 & 0.82 & -0.18 & 0.83 & -0.91 & $0.40 * *$ & -1.07 & 0.34 \\
\hline Other & -0.30 & $0.74 * *$ & -0.22 & 0.80 & -0.10 & 0.91 & 0.13 & 1.14 \\
\hline Unknown & 0.02 & 1.02 & 0.06 & 1.06 & -0.02 & 0.98 & 0.15 & 1.16 \\
\hline Mother's civil status & \multicolumn{2}{|c|}{$(0.00)$} & \multicolumn{2}{|c|}{$(0.40)$} & \multicolumn{2}{|c|}{$(0.17)$} & \multicolumn{2}{|c|}{$(0.71)$} \\
\hline RC: Married & 0 & 1 & 0 & 1 & 0 & 1 & 0 & 1 \\
\hline Single & 0.44 & $1.55^{* *}$ & 0.32 & 1.37 & -0.68 & 0.51 & -1.10 & 0.33 \\
\hline Legally separated & 0.88 & $2.42 * *$ & 0.61 & 1.84 & -1.79 & $0.17 *$ & -18.73 & 0.00 \\
\hline Widow & 0.84 & $2.31 * *$ & -18.80 & 0.00 & -0.12 & 0.88 & -18.52 & 0.00 \\
\hline Divorced & 0.62 & $1.86^{* *}$ & 0.24 & 1.28 & -1.05 & $0.35^{*}$ & -18.99 & 0.00 \\
\hline Unknown & 0.11 & 1.12 & 0.09 & 1.09 & -0.47 & 0.63 & -0.64 & 0.53 \\
\hline Expulsion method & \multicolumn{2}{|c|}{$(0.00)$} & & & \multicolumn{2}{|c|}{$(0.01)$} & \multicolumn{2}{|c|}{$(0.00)$} \\
\hline RC: Spontaneous & 0 & 1 & 0 & 1 & 0 & 1 & 0 & 1 \\
\hline Vacuum extraction & -0.53 & $0.59 * *$ & -0.54 & $0.58 * *$ & 0.41 & $1.50 * *$ & 0.12 & 1.13 \\
\hline Forceps & -0.60 & $0.55 * *$ & -0.67 & $0.51 * *$ & 0.20 & 1.22 & 0.23 & 1.25 \\
\hline Caesarean & 0.72 & $2.05 * *$ & 0.76 & $2.13 * *$ & 0.18 & 1.20 & 0.57 & $1.76^{* *}$ \\
\hline Breech delivery & 0.59 & 1.80 & 0.81 & 2.26 & 1.61 & $5.01 *$ & 2.09 & $8.04 * *$ \\
\hline Constant & -4.05 & $0.02 * *$ & -4.07 & $0.02 * *$ & -4.01 & $0.02 * *$ & -4.16 & $0.02 * *$ \\
\hline
\end{tabular}

Note: Significance level for the variable as a whole is expressed in brackets; ${ }^{*}=\mathrm{p}<0.05 ; * *=\mathrm{p}<0.01$. 
dataset. Women who had their child between the ages of 30 and 39 had an increased risk that their child experienced a too slow weight gain.

Therefore, what this study shows is that high maternal age has an immediate negative effect on birth weight. After birth, low birth weight children start catching up with normal birth weight children, but the children of higher aged mothers do not have any advantage here. On the contrary, the Walloon data suggest that children of women who had their child after age 30 even had a disadvantage. In addition, it takes a long time, actually several years, for low birth weight children to catch up with normal birth weight children, from which we can conclude that the impact of high maternal age on child health after birth as proxied by weight gain is long-term but not permanent.

Interesting though these findings are, some limitations of this study should be noticed. First of all, one could question the appropriateness of using weight gain as a proxy for child health, since studies using other proxies of child health, such as physical and cognitive development, show a permanent negative impact. The use of weight gain as a proxy for child health after birth in this study was dictated by the nature of the variables included in the two regional datasets used. This study shows that high maternal age may not have a permanent impact on all indicators of a child's health. Therefore, the impact of high maternal age on child health needs to be explored further, and this on the basis of datasets that include in addition to child weight data also other indicators of child health.

A second limitation of our study is the fact that attrition rates are high, in particular in the Walloon dataset. The exact consequences of this attrition are not clear, because it is hard to judge whether attrition is selective. Comparing the set of children for which data at birth is available and the set of children for which data at age 1 is available suggests that these two sets do not differ too strongly as far as the distributions of background variables is concerned. In future research, strategies to prevent attrition (managerial issue), or statistical imputation methods may be useful. A combined analysis with vital registration is also preferable if data are accessible. Further, sufficient attention must be paid to reducing missing and unknown information. Information for some variables in both datasets was not systematically recorded (information often missing for socio-demographic variables) or recorded in a non-standardised manner (e.g., recording of levels of educational attainment in the K\&G dataset without making use of the ISCED97 classification). And finally, the socio-demographic information available in both datasets was all in all still limited. It would be preferable if both datasets included a broader range of socio-demographic variables for both mother and father.

The above limitations notwithstanding, these results suggest that the postponement of motherhood that is currently occurring throughout the Western world could have negative health consequences for children, in particular if the proportion of births at high ages (e.g., after age 40) will increase markedly. At the same time, these results suggest that the effects of late motherhood should not be overstated. Although births with low birth weight are more likely to occur to 
women who postpone motherhood, in the long run these children will probably catch up with other children as far as birth weight is concerned. However, additional research is needed before one can draw definite conclusions in this regard.

\section{Acknowledgements}

This analysis was prepared during the author's stay at the Institut de démographie, Université catholique de Louvain in 2004-2005 within the framework of European Commission funded Research Training Network (RTN) "Contemporary Family Formation Processes and Health Outcomes in Early Infancy in Europe" (Promoters Professor Dr. Godelieve Masuy-Stroobant and Professor Dr. Catherine Gourbin-European Community's Human Potential Programme under contract HPRN-CT-2001-00234). The author thanks Ms. Bea Buysse (Kind en Gezin) for providing access to the IKAROS database and Dr. Marie-Christine Mauroy (ONE) for providing access to the BDMS database. Many thanks also to Mr. Samuel Ndame Ebongue and Ms. Anne Liesse (ONE) and to Mr. Bernard Masuy (Université catholique de Louvain) for preparing the data for analysis. ${ }^{10}$ Mr. Mathieu Roelants (Faculty of Sciences, Vrije Universiteit Brussel) provided access to the 2005 Flemish growth curves. The author acknowledges useful comments and suggestions from the aforementioned persons, as well as from Professor Dr. Guillaume Wunsch (Université catholique de Louvain, Belgium), Professor Dr. Leiv S. Bakketeig (University of Southern Denmark) Dr. Mika Gissler (STAKES, Finland), Dr. Maria Loghi (l'Istituto nazionale di statistica, Italy), and Professor Dr. Alison Macfarlane (City University, UK), RTN fellows at various network meetings, and the anonymous reviewers of this paper. Finally, I would like to thank Professor Dr. Aart Liefbroer (NIDI, The Netherlands) for his extensive help with the revisions of this article, which greatly contributed to its acceptance by the reviewers.

\section{References}

Astolfi, P. and L. A. Zonta. 2002. "Delayed maternity and risk at delivery." Paediatric and Perinatal Epidemiology 16: 67-72.

Blondel, B., M. D. Kogan, G. R. Alexander, N. Dattani, M. S. Kramer, A. Macfarlane, and S. W. Wen. 2002. "The impact of the increasing number of multiple births on the rates of preterm birth and low birth weight: an international study." American Journal of Public Health 92(8): 1323-1330.

10 One should note that K\&G and ONE are the child and maternal health agencies of the Belgian Dutch- and French-speaking communities respectively. They were both part of the former national ONE (Office de la Naissance et de l'Enfance) founded in 1919. 
Boardman, J. D., D. A. Powers, Y. C. Padilla, and R. A. Hummer. 2002. "Low birth weight, social factors and developmental outcomes among children in the United States." Demography 39(2): 353-368.

Bréart, G. 1997. "Delayed childbearing." European Journal of Obstetrics and Gynecology and Reproductive Biology 75: 71-73.

Buekens, P., G. Masuy-Stroobant, and T. Delvaux. 1998. "High birth weights among infants of North African immigrants in Belgium." American Journal of Public Health 88(5): 808-810.

Buitendijk, S., J. Zeitlin, M. Cuttini, J. Langhoff-Roos, and J. Bottu. 2003. "Indicators of fetal and infant health outcomes." European Journal of Obstetrics and Gynecology and Reproductive Biology 111: 66-77.

Cleary-Goldman, J. C., F. D. Malone, J. Vidaver, R. H. Ball, D. A.Nyberg, C. H. Comstock, G. R. Saade, K. A. Eddleman, S. Klugman, L. Dugoff, I.E. Timor-Tristch, S. D. Craigo, S. R. Carr, H. M. Wolfe, D. W. Bianchi, M. D'Alton, for the FASTER Consoritum. 2005. "Impact of maternal age on obstetric outcome." Obstetrics and Gynecology 105(5, 1): 983-990.

Council of Europe. 2004. Recent demographic developments in Europe. Council of Europe, Strasbourg.

D’Addio, A. C. and M. Mira d'Ercole. 2005. "Trends and Determinants of Fertility Rates in OECD Countries: The Role of Policies.” OECD Social, Employment and Migration Working Papers No. 27, Paris, OECD, 2 November 2005.

Dubois, L. and M. Girard. 2006. "Early determinants of overweight at 4.5 years in a population-based longitudinal study." International Journal of Obesity 30: 610-617.

Flemish growth curve. 2005. Vrije Universiteit Brussel, Anthropotenetica \& Katholieke Universiteit Leuven, Jeudgezondheidszorg met de steun van de Vlaamse Regering «www.vub.ac.be/groeicurven»

Foix-L'Hélias and B. Blondel. 2000. "Changes in risk factors of preterm delivery in France between 1981 and 1995." Paediatric and Perinatal Epidemiology 14: 314323.

Gourbin, C. and G. Masuy-Stroobant. 1993. "Are live and stillbirths comparable all over Europe? Legal definitions and vital registration data processing." Working document. Institut de Démographie, Université catholique de Louvain, Louvain-la-Neuve.

Grummer-Strawn, L.M. and Z. Mei. 2004. "Does breastfeeding protect against pediatric overweight? Analysis of Longitudinal Data from the Centers for Disease Control and Prevention Pediatric Nutrition Surveillance System.” Pediatrics 113(2): e81-e86.

Haelterman, E., G. Bréart, J. Paris-Llado, M. Dramaix, and C. Tchobroutsky. 1997. "Effect of uncomplicated chronic hypertension on the risk of Small-for-Gestational Age Birth." American Journal of Epidemiology: 689-695.

Hemminki, E. and M. Gissler. 1996. "Births by younger and older mothers in a population with late and regulated childbearing: Finland 1991." Acta Obstetricia et Gynecologica Scandinavica 75: 19-27.

Henriet, L. and M. Kaminski. 2001. "Impact of induced abortions on subsequent pregnancy outcome: the 1995 French national perinatal survey." British Journal of Obstetrics and Gynaecology 108: 1036-1042.

Jaakkola, N., M. S. Jaakkola, M. Gissler, and J. J. K. Jaakkola. 2001. "Smoking during pregnancy in Finland: determinants and trends, 1987-1997." American Journal of Public Health 91(2): 284-286. 
Kallan, J. E. 1993. "Race, intervening variables and two components of low birth weight." Demography 30(3): 489-506.

Kiernan, C. and K. E. Pickett. 2006. "Marital status disparities in maternal smoking during pregnancy, breast-feeding and maternal depression." Social Science and Medicine 63: 335-346.

Kögel, T. 2004. "Did the association between fertility and female employment within OECD countries really change its sign?" Journal of Population Economics 17(1): 45-65.

Kramer, M. S. 1987. "Determinants of low birth weight: methodological assessment and meta-analysis." Bulletin of the World Health Organizations 65(5): 663-737.

Masuy-Stroobant, G. and C. Gourbin. 1995. "Infant health and mortality indicators: their accuracy for monitoring the socio-economic development in the Europe of 1994." European Journal of Population 11(1): 63-84.

Masuy-Stroobant, G. 1996. "Santé et mortalité des enfants en Europe. Child health and mortality in Europe." In: Chaire Quetlet. 1994. Institut de démographie/Ecole de Santé Publique, UCL/ULB, Louvain-la-Neuve: Academia-Bruylant/L'Harmattan, pp. 337-366.

Matsuo, H. 2005. "The health consequences of low birth weight: literature review and critique." UCL working paper 23.

Mei, Z., L. M. Grummer-Strawn, D. Thompson, and W. H. Dietz. 2004. "Shifts in percentiles of growth during early childhood: analysis of longitudinal data from the California Child Health and Development study." Pediatrics 113(6): e617-e627.

Misra, D. P., N. Astone, and C. D. Lynch. 2005. "Maternal smoking and birth weight: interaction with parity and mother's own in utero exposure to smoking." Epidemiology 16(3): 288-293.

OECD. 1999. Classifying Educational Programmes, Manual for ISCED - 97, Implementation in OECD Countries. 1999 Edition, OECD, Paris.

Parsons, T. J., C. Power, and O. Manor. 2001. "Fetal and early life growth and body mass index from birth to early adulthood in 1958 British cohort: longitudinal study." British Medical Journal 323: 1331-1335.

Raatikainen, K., N. Heiskanen, and S. Heinonen. 2005. "Marriage still protects pregnancy." International Journal of Obstetrics and Gynecology 112: 1411-1416.

Reichman, N. E. and D. L. Pagnini. 1997. "Maternal age and birth outcomes: Data from New Jersey." Family Planning Perspectives 29: 268-272, 295.

Sherry, B., Z. Mei, L. Grummer-Strawn, and W. H. Dietz. 2003. "Evaluation of and recommendations for growth references for very low birth weight $(<1500 \mathrm{~g})$ infants in the United States." Pediatrics 111(4): 750-758.

Studiecentrum voor Perinatale Epidemiologie. 2005. Perinatale activiteiten in Vlanderen 2004. Brussels: Studiecentrum voor Perinatale Epidemiologie.

Sweet, M. P., J. E. Hodgman, I. Pena, L. Barton, Z. Pavlova, and R. Ramanathan. 2003. "Two year-outcome of infants weighing 600 grams or less at birth and born 1994 through 1998." Obstetrics and Gynaecology 101(1): 18-23.

Tough, S. C., C. Newburn-Cook, D. W. Johnston, L. W. Svenson, S. Rose, and J. Belik. 2002. "Delayed childbearing and its impact on population rate changes in lower birth weight, multiple birth, and preterm delivery." Paediatrics 100(3).

Walton, S., H. Bedford, C. Dezateux, and the Millennium Cohort Study Child Health Group. 2006. "Use of personal child health records in the UK: findings from the millennium cohort study." British Medical Journal 332: 269-270. 
World Health Organization. 'Health for All' database. «http://hfadb.who.dk/hfa/»

Yang, Q., S. Greenland, and W. D. Flanders. 2006. “Associations of maternal age- and parity- related factors with trends in low birth rates: United States, 1980 through 2000." American Journal of Public Health 96(5): 856-861.

Young, T. K. 1998. Population and Health. Oxford: Oxford University Press. 